\title{
Conduction disorders after aortic valve replacement with rapid-deployment bioprostheses: early occurrence and one-year evolution
}

\author{
Augusto D'Onofrio ${ }^{1 \#}$, Chiara Tessari ${ }^{1 \#}$, Lorenzo Bagozzi ${ }^{1}$, Federico Migliore ${ }^{1}$, Claudia Filippini ${ }^{2}$, \\ Giorgia Cibin ${ }^{1}$, Rita Pesce ${ }^{1}$, Annalisa Francescato ${ }^{1}$, Gino Gerosa ${ }^{1}$ \\ ${ }^{1}$ Department of Cardiac, Thoracic, Vascular Sciences and Public Health, University of Padova, Padova, Italy; ${ }^{2}$ Department of Surgical Sciences, \\ University of Turin, Turin, Italy \\ \#These authors contributed equally to this study and should be both considered first authors. \\ Correspondence to: Augusto D’Onofrio, MD, PhD. Cardiac Surgery Unit, Department of Cardiac, Thoracic, Vascular Sciences and Public Health, \\ University of Padova, Via Giustiniani 2, 35128, Padova, Italy. Email: augusto.donofrio@unipd.it.
}

Background: Rapid-deployment bioprostheses represent one of the newest aortic valve substitutes introduced into clinical practice. The aim of this retrospective single-center study was to evaluate the occurrence of conduction disorders (CDs) after rapid-deployment aortic valve implantation at discharge and at 1-year follow-up, and to identify risk factors for CDs and permanent pacemaker implantation (PPI).

Methods: All patients who reached 1-year follow-up after isolated or combined aortic valve replacement (AVR) with rapid-deployment bioprostheses (Intuity Elite, Edwards Lifesciences, Irvine, CA) at our institution were included in this study. Standard 12-lead electrocardiograms (ECGs) were recorded before the procedure (within 24 hours), after the procedure as soon as the patient was moved to the intensive care unit (ICU), every day during in-hospital stay and at 1-year follow-up. The primary endpoint was the incidence of postoperative CDs at discharge and at 1-year follow up. Patients were divided in two groups: those who developed the primary endpoint (Group CD) and those who didn't (Group Non-CD).

Results: A total of 98 consecutive patients were included in the study. At discharge, the primary endpoint occurred in 40 patients (40.8\%). In particular, new CDs and PPI occurred in $33(33.7 \%)$ and in 7 (7.1\%) patients, respectively. Valve size was the only independent predictor of primary endpoint at discharge. At 1-year, 30 patients $(31.3 \%)$ presented with CDs or pacemaker-induced rhythm. In particular, in 25 patients of Group CD (64.1\%), 1-year follow-up ECG revealed the persistence of the same CD as at discharge or pacemaker-induced rhythm, while 14 patients (35.9\%) showed recovery of their CD. Age and prosthesis size were identified as independent predictors of CDs/pacemaker-induced rhythm at 1-year follow-up.

Conclusions: According to our data, nearly $40 \%$ of patients develop a new CD after rapid-deployment aortic valve implantation. Of these, one third recover after one year. Bioprosthesis size and age were identified as independent risk factors for occurrence of CD after surgery.

Keywords: Aortic valve replacement (AVR); heart valve prosthesis; sutureless; rapid deployment; conduction disorders (CDs); pacemaker

Submitted Feb 12, 2020. Accepted for publication Jul 14, 2020.

doi: 10.21037/acs-2020-surd-14

View this article at: http://dx.doi.org/10.21037/acs-2020-surd-14 


\section{Introduction}

Rapid-deployment bioprostheses (RDB) represent one of the newest aortic valve substitutes introduced into clinical practice. Their design is based on bovine pericardial leaflets mounted on a stent with a balloon-expandable skirt placed below it. The latter allows anchoring and sealing of this prosthesis into the annulus and into the left ventricular outflow tract (LVOT) similarly to balloon-expandable transcatheter aortic valve (TAVI) prostheses. The main advantages of RDB are related to the reduction of procedural time, especially during combined procedures, to the simplification of minimally invasive approaches and to the improvement of hemodynamic performance. However, because of its analogy with TAVI anchoring, the risk of postoperative conduction disorders (CDs) and permanent pacemaker implantation (PPI) represents a potential concern. In fact, in TAVI it has been demonstrated that the implantation height of the stent into the LVOT is associated with a higher risk of postoperative CDs and PPI (1). The incidence of PPI after RDB implantation ranges between $5 \%$ and $11 \%(2-4)$, while postoperative CDs occur in nearly one third of treated patients (5). Despite these results, many published studies end their observation within the hospitalization period, not evaluating how these CDs may change over time. In order to fulfill these gaps, the aim of this retrospective single-center study was to evaluate the occurrence of CDs after RDB implantation at discharge and at 1-year follow-up, and to identify risk factors for CDs and PPI.

\section{Methods}

\section{Study population}

All consecutive patients who reached 1-year follow-up after aortic valve replacement (AVR) for severe aortic stenosis with the RDB Intuity Elite Valve System (Edwards Lifesciences, Irvine, CA) at our institution were included in this study. Both isolated and combined procedures were considered. The choice to implant an Intuity valve was based on the surgeon's preference and experience. Surgical operations were performed either through full sternotomy or minimally invasive approaches (upper ministernotomy or right mini-thoracotomy in the second intercostal space) according to surgeon preference. The Intuity valve was implanted according to the standard technique $(2,3,6)$. In particular, annular decalcification was done as for conventional AVR. Patients with extremely severe annular calcifications going deep into the aortic annulus that required extensive debridement with annular discontinuation could not receive the Intuity device as per the manufacturer's instruction for use. Sizing was performed intraoperatively as for a conventional surgical operation, a preoperative angio-computed tomography (Angio-CT) scan was not routinely performed. Preoperative variables were defined according to the EuroSCORE II definitions (7). Patients with preoperative permanent pacemaker or with incomplete electrocardiographic data were excluded from the analysis.

\section{Cardiac rhythm evaluation}

Standard 12-lead electrocardiograms (ECGs) were recorded before the procedure (within 24 hours), after the procedure as soon as the patient was moved to the intensive care unit (ICU) and every day during in-hospital stay. Continuous telemetry monitoring was routinely performed in all patients for at least the first 72 hours after the operation or for a longer period if needed. Additional ECGs were performed if any alteration from the baseline rhythm appeared and after its recovery. A 12lead ECG was obtained in all included patients at 1-year follow-up. All ECGs were analyzed by two independent physicians blinded to each other (CT, LB). In particular, we looked for left bundle branch block (LBBB) (complete and incomplete), right bundle branch block (RBBB) (complete and incomplete), left hemiblock, intraventricular conduction delays (IVCD), atrio-ventricular blocks (AVB). The diagnosis of CDs was based on the recommendations of the American Heart Association/American College of Cardiology/Heart Rhythm Society for the standardization and interpretation of cardiac rhythm (8). In addition, strict criteria for LBBB and for IVCD were applied according to Strauss $(9,10)$. The requirement for PPI was determined by an electrophysiologist according to the standardized criteria from the European Society of Cardiology/European Heart Rhythm Association and the American Heart Association/ American College of Cardiology/Heart Rhythm Society guidelines for device-based therapy of cardiac rhythm abnormalities $(11,12)$. Although CDs requiring temporary pacemaker (PM) appeared within the first 24 hours after operation, an observation period of 7 or even 15 days was required before implanting a permanent pace-maker (Class 1 recommendation). Moreover, at 1-year followup to evaluate the PM dependency in patients with a paced baseline ECG, the PM was programmed to VVI 

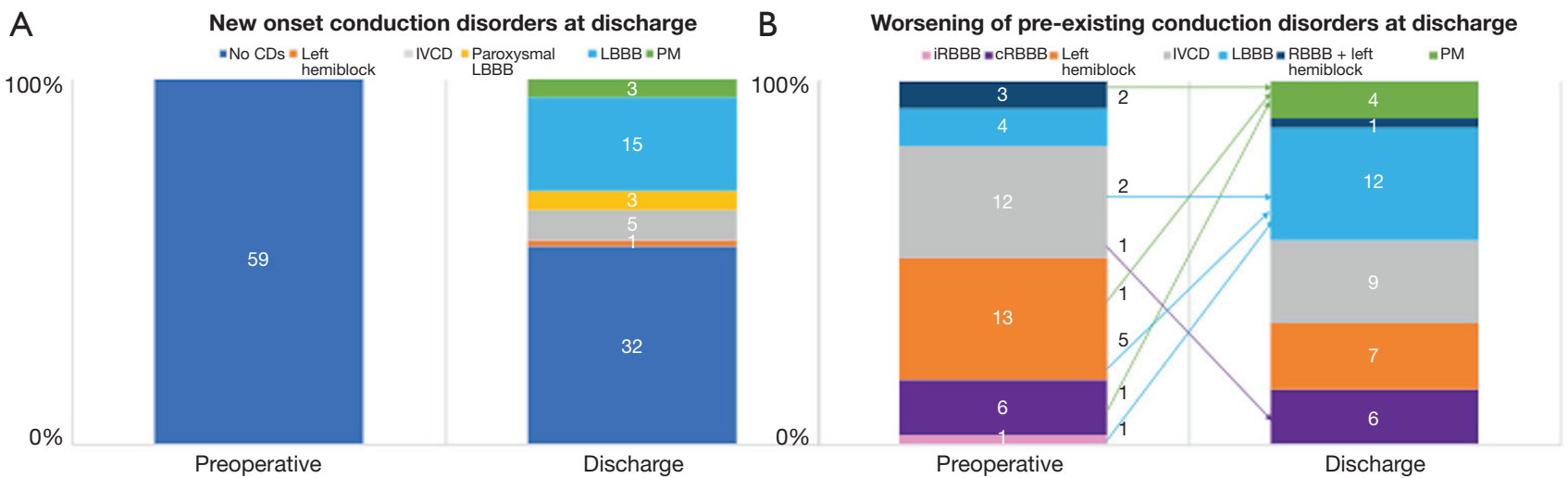

Figure 1 New onset conduction disorders at discharge in patients without preoperative conduction disorders (A) and in patients with preoperative conduction disorders (B).

at the lowest possible rate and the underlying rhythm was observed. Pacemaker dependency was defined if the rhythm continued to be paced or if there was a complete atrioventricular block or atrial fibrillation with inadequate ventricular response, whereas non-PM dependency was defined if sinus rhythm or atrial fibrillation with adequate ventricular response occurred.

Primary endpoint was the incidence of postoperative CDs at discharge and at 1-year follow up. Secondary endpoint was the evaluation of patients' conduction pathways at 1-year follow-up.

Follow-up was performed at our outpatient clinic or, as an alternative, with a phone interview, asking patients to send the most recent ECG and cardiologic evaluation to our institution. One-year follow up was completed in all patients.

\section{Statistical analysis}

For continuous variables, data are reported as mean with standard deviation, while for categorical variables, data are reported as absolute number and percentage. Comparison between groups for continuous variables was performed with t-test or Wilcoxon-Mann-Whitney according to type of distribution; comparison between groups for categorical variables was performed with Chi-square or Fisher exact test as appropriate; for paired categorical variables $\mathrm{McNemar}$ test was used.

A univariate logistic regression analysis was performed to test which covariates would be considered in subsequent multivariable logistic regression models $(\mathrm{P}<0.05)$ both for CDs and PPI at discharge. After a multicollinearity evaluation, other variables with a biologically relevant correlation to the onset of CDs (age, preoperative ejection fraction, technical aspects that might cause ischemic myocardial injuries, pre-existing CDs) were also included to identify independent predictors of new-onset or worsening CDs in the multivariable analysis. Univariate and multivariable analyses were also performed considering the same variables to identify predictors of PPI and predictors of CDs at 1-year follow-up. The odds ratios and their corresponding $95 \%$ confidence intervals were provided. A P value of $<0.05$ with a 2 -tailed test was considered statistically significant. Statistical analyses were conducted using IBM SPSS Statistics, version 19 (SPSS, Inc., Chicago, Illinois).

\section{Results}

\section{In-hospital period}

From July 2015 to September 2017, 127 consecutive patients underwent Intuity valve implantation for severe aortic valve stenosis at our institution. Implantation success was achieved in 124 patients $(97.6 \%)$; of these, 25 were excluded from this study because of preoperative permanent PM or incomplete ECG data. In addition, one patient $(1.0 \%)$ died from multiorgan failure before discharge. The remaining 98 patients $(79.0 \%)$ were successfully discharged and represent the population of this study. At discharge, the primary endpoint occurred in 40 patients (40.8\%). In particular, new CDs (or worsening of pre-existing rhythm abnormalities) and PPI occurred in 33 (33.7\%) and in 7 (7.1\%) patients, respectively. Left-sided CDs formed the majority $(32,80 \%)$ with LBBB being the most frequent CD $(23,57.5 \%)$. Figure 1 shows the different types of cardiac rhythm before and after Intuity implantation. Table 1 
Table 1 Predictors of new onset conduction disorders at discharge

\begin{tabular}{|c|c|c|c|c|c|c|c|}
\hline $\begin{array}{l}\text { Baseline and intraoperative } \\
\text { characteristics }\end{array}$ & $\begin{array}{l}\text { Overall } \\
(n=98)\end{array}$ & $\begin{array}{l}\text { Group CD } \\
(n=40)\end{array}$ & $\begin{array}{l}\text { Group non-CD } \\
(n=58)\end{array}$ & $\begin{array}{l}\text { Univariate analysis } \\
\text { ( } \mathrm{P} \text { value) }\end{array}$ & \multicolumn{3}{|c|}{ Multivariable analysis } \\
\hline Age (years) & $72.2 \pm 7.8$ & $72.9 \pm 7.0$ & $71.8 \pm 8.3$ & 0.503 & 1.035 & $0.973-1.102$ & 0.274 \\
\hline Gender & & & & 0.148 & - & - & - \\
\hline Male & 60 (61.2) & $28(70.0)$ & 32 (55.2) & & & & \\
\hline Arterial hypertension & $72(73.5)$ & $32(80.0)$ & $40(69.0)$ & 0.253 & - & - & - \\
\hline Diabetes mellitus & $26(26.5)$ & $10(25.0)$ & $16(27.6)$ & 0.820 & - & - & - \\
\hline NYHA functional class & & & & 0.699 & - & - & - \\
\hline I & $1(1.0)$ & $1(2.5)$ & $0(0)$ & & & & \\
\hline IV & $6(6.1)$ & $3(7.5)$ & $3(5.2)$ & & & & \\
\hline LVEF (\%) & $58.6 \pm 10.0$ & $58.6 \pm 10.0$ & $58.5 \pm 10.1$ & 0.739 & 1.01 & $0.963-1.059$ & 0.683 \\
\hline EuroScore II (\%) & $1.9 \pm 1.5$ & $1.7 \pm 1.1$ & $2.0 \pm 1.7$ & 0.957 & - & - & - \\
\hline Cardiac rhythm & & & & 0.302 & 3.346 & $0.530-21.122$ & 0.199 \\
\hline Sinus rhythm & $89(90.8)$ & $38(95.0)$ & $51(87.9)$ & & & & \\
\hline Atrial fibrillation & $9(9.2)$ & $2(5.0)$ & 7 (12.1) & & & & \\
\hline $\begin{array}{l}\text { Atrioventricular block I } \\
\text { (of patients in sinus rhythm) }\end{array}$ & $37(41.6)$ & $15(40.5)$ & $22(42.3)$ & 0.829 & - & - & - \\
\hline \multicolumn{8}{|c|}{ Right-sided conduction disorder at baseline } \\
\hline Right-sided & $10(10.2)$ & $4(10.0)$ & $6(10.3)$ & 1 & 1.364 & $0.269-6.289$ & 0.691 \\
\hline No right-sided & $88(89.8)$ & $36(90.0)$ & $52(89.7)$ & & & & \\
\hline \multicolumn{8}{|c|}{ Left-sided conduction disorder at baseline } \\
\hline Left-sided & $29(29.6)$ & $9(22.5)$ & $20(34.5)$ & 0.262 & 2.054 & $0.716-5.895$ & 0.181 \\
\hline No left-sided & $69(70.4)$ & $31(77.5)$ & $38(65.5)$ & & & & \\
\hline \multicolumn{8}{|l|}{ Type of operation } \\
\hline Isolated AVR & $56(57.1)$ & $19(47.5)$ & $37(63.8)$ & 0.210 & - & - & - \\
\hline CABG & $38(38.8)$ & $19(47.5)$ & $19(32.8)$ & & & & \\
\hline Mitral replacement & $1(1.0)$ & $1(2.5)$ & $0(0)$ & & & & \\
\hline ASD closure & $3(3.1)$ & $1(2.5)$ & $2(3.5)$ & & & & \\
\hline
\end{tabular}

Table 1 (continued) 


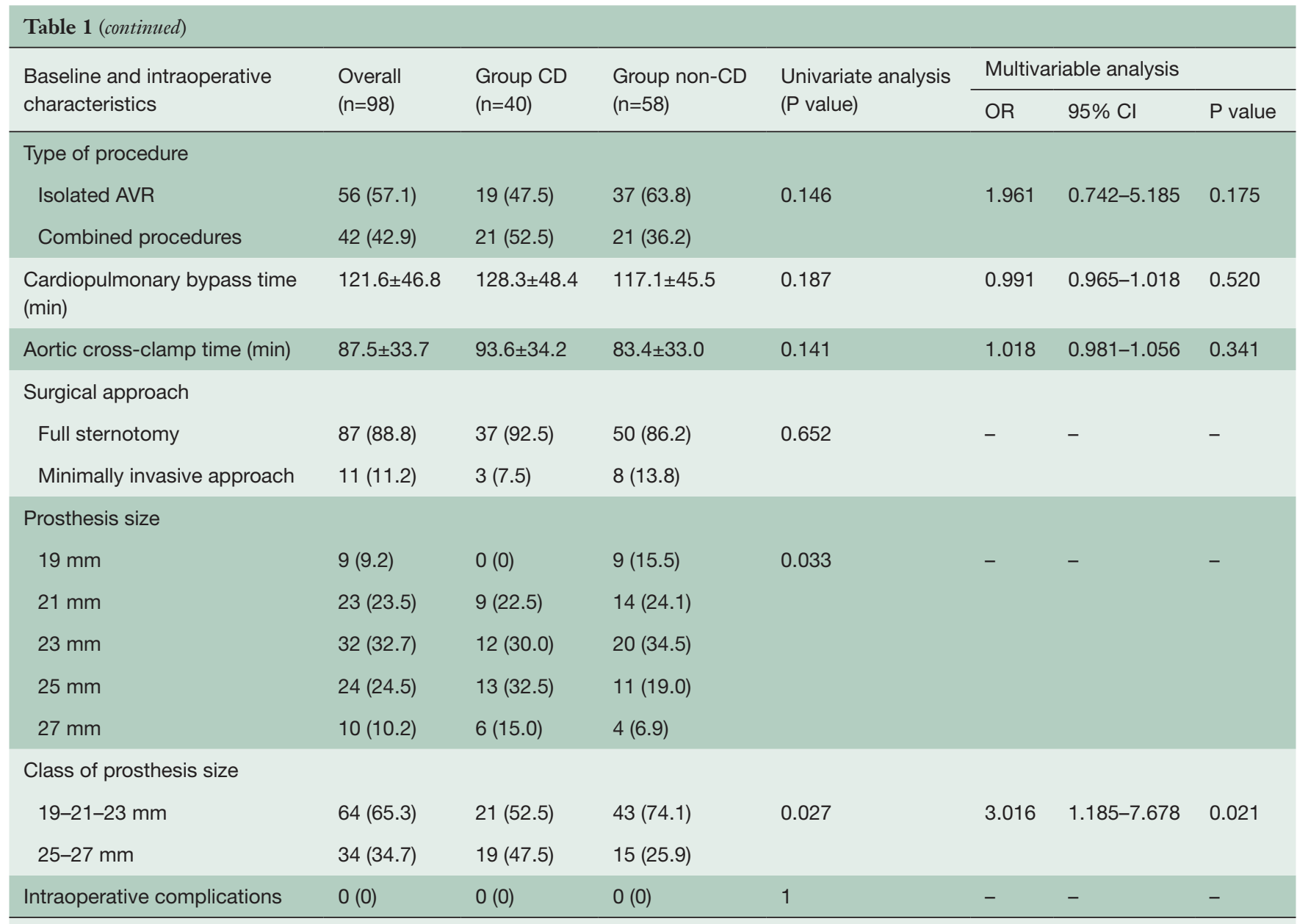

The data are shown as mean \pm standard deviation or $n(\%)$. ASD, atrial septal defect; AVR, aortic valve replacement; CABG, coronary artery bypass grafting; CD, conduction disorder; Cl, confidence interval; LVEF, left ventricle ejection fraction; NYHA, New York Heart Association; OR, odds ratio.

depicts preoperative and intraoperative characteristics of the study population. Baseline characteristics were similar between those who developed primary endpoint (Group CD) and those who did not (Group Non-CD). Intraoperative data were similar between groups, except for valve size. Patients in the CD group were more likely to receive a $25 \mathrm{~mm}$ or a $27 \mathrm{~mm}$ device $(32.5 \%$ and $15.0 \%$ in Group CD vs. $19.0 \%$ and $6.9 \%$ in Group Non-CD, respectively; $\mathrm{P}=0.0329$ ). At multivariable analysis, valve size was the only independent predictor of the primary endpoint at discharge. In particular, we decided to evaluate valve sizes dividing them into two categories according to the required balloon inflation pressure (4.5 atmospheres for 19, 21 and $23 \mathrm{~mm} v s .5 .0$ atmospheres for 25 and $27 \mathrm{~mm}$ ). Larger devices ( 25 and $27 \mathrm{~mm}$ ) were more related to new onset CDs than the smaller ones. Indications for PPI were: permanent complete atrio-ventricular (AV) block in four (57.1\%) patients; paroxysmal complete AV block alternated with: low-rate atrial fibrillation in one patient, sinus rhythm and right bundle branch block (RBBB) associated with left hemiblock in one patient, and sinus rhythm without CDs but causing syncope in one patient. Patients with preoperative CDs, in particular right-sided CDs, were more likely to receive a pacemaker. Pre-operative CDs were present in four out of seven patients who underwent postoperative PPI $(57.1 \%, \mathrm{P}=0.0119)$. Of these, preoperative right-sided CDs were present in three patients (42.9\%, $\mathrm{P}=0.022$ ) (Table 2). The multivariable logistic regression model identified the presence of a preoperative right-sided $\mathrm{CD}$ as an independent predictor of PPI after 
Table 2 Predictors of postoperative permanent pace-maker implantation

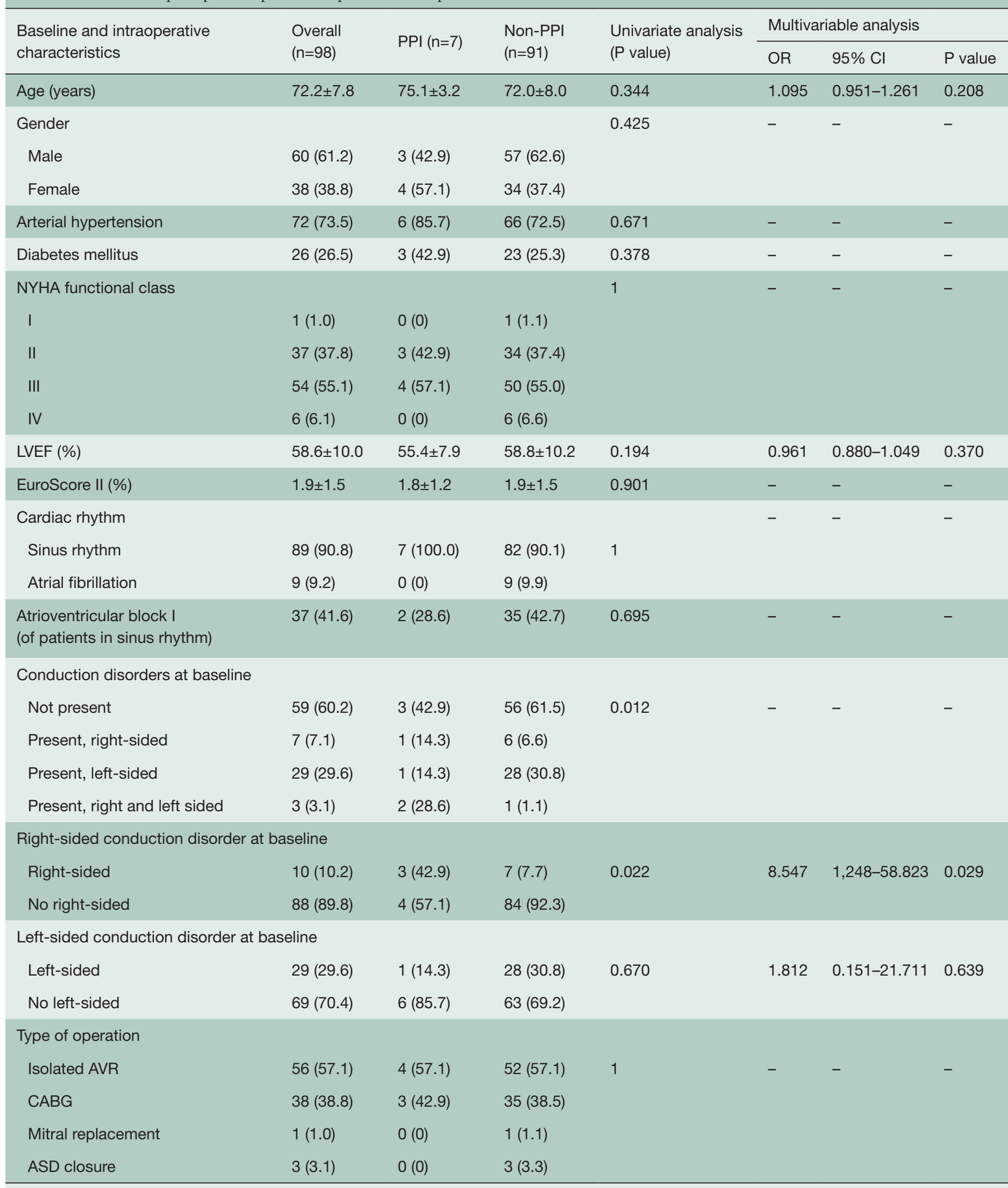

Table 2 (continued) 


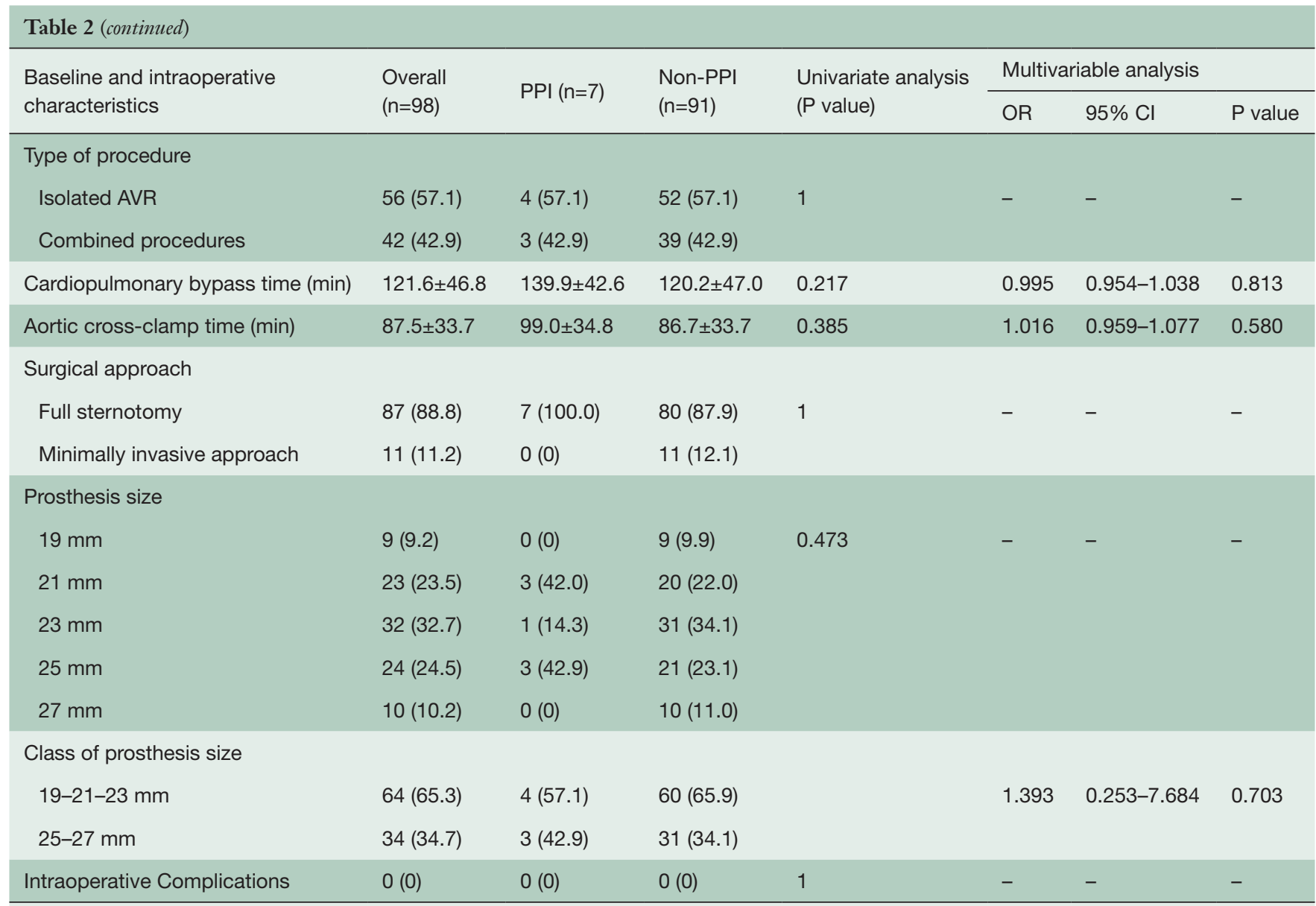

The data are shown as mean \pm standard deviation or $n(\%)$. ASD, atrial septal defect; AVR, aortic valve replacement; CABG, coronary artery bypass grafting; CD, conduction disorder; Cl, confidence interval; LVEF, left ventricle ejection fraction; NYHA, New York Heart Association; OR, odds ratio.

Intuity implantation.

\section{One-year follow-up}

At 1-year follow-up, two patients died for cancer (2.0\%), one in each group. No sudden death occurred. Two patients $(2.0 \%)$ underwent PPI during follow-up. Twentynine patients $(30.2 \%)$ presented with CDs or PM-induced rhythm at ECG. In particular, in 24 patients of Group CD (61.5\%), 1-year follow-up ECG revealed either the persistence of the same CD found at discharge or PMinduced rhythm, while in 15 patients $(38.5 \%)$ there was a recovery or an improvement of CD (Figure $2 A$ ). Pacemaker dependency was observed in 5 of the 7 patients who required postoperative PPI (71.4\%), whereas two PMs were on "stand-by": one patient without preoperative CDs who received a PM because of symptomatic paroxysmal complete AV block, and one patient with preoperative RBBB who received a PM because of paroxysmal complete AV block alternating with low-rate atrial fibrillation. At 1-year followup, their ECGs revealed sinus rhythm associated with complete LBBB, and sinus rhythm associated with complete RBBB, respectively. On the other hand, five patients of Group Non-CD (8.8\%) showed a new-onset CD at 1-year follow-up; in particular, two patients developed a RBBB, one patient with preoperative IVCD developed a LBBB, and two patients with preoperative RBBB needed PPI: one for sick-sinus syndrome and one for atrial fibrillation with inadequate drug response. We did not observe complete AV block development at 1-year follow-up in Group NonCD (Figure 2B). Multivariable analysis showed that age and prosthesis size were identified as independent predictors of 


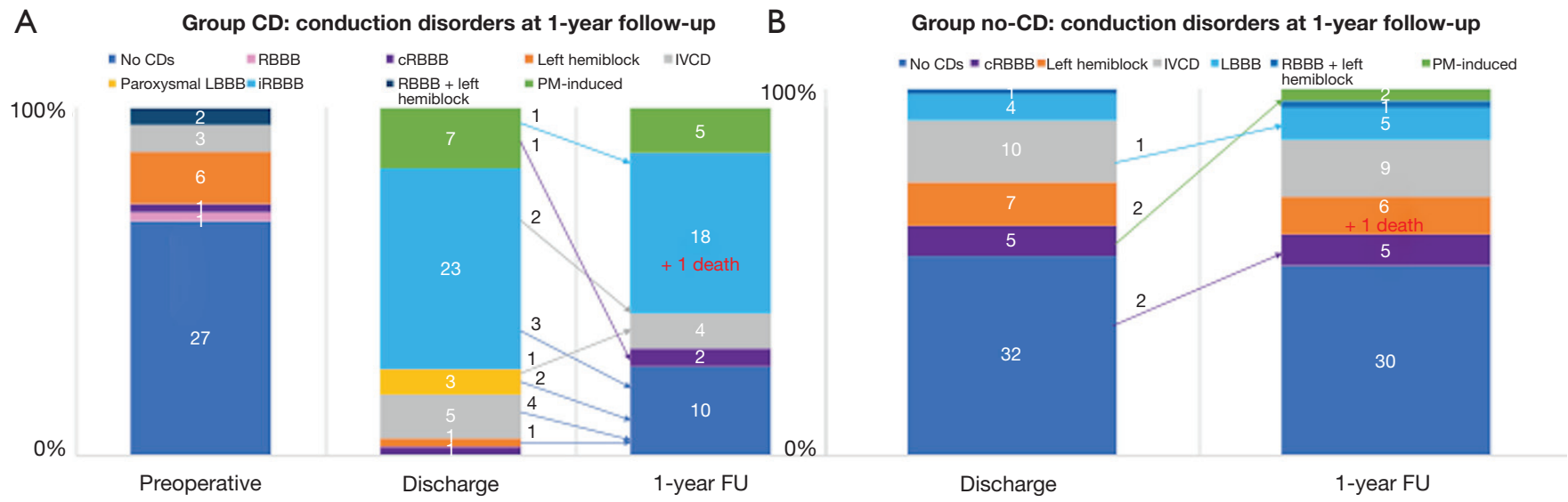

Figure 2 Conduction disorders at 1-year follow-up in patients discharged with new onset conduction disorders (A) and in patients discharged without new onset conduction disorders (B).

CDs/PM-induced rhythm at 1-year follow-up (Table 3).

\section{Discussion}

The main finding of this study is that $40 \%$ of patients develop new CDs or worsening of a preexisting CD after the implantation of a RDB in the aortic position. Of these, one third recover after one year. The rate of PPI is $7.1 \%$ and, after one year, PM dependency rate is $71.4 \%$. A possible explanation for the development of postoperative CDs is related to the subannular skirt that opens into the LVOT and compresses the conduction system. The His bundle penetrates the interventricular septum immediately below the ventricular-arterial junction, between the right and the non-coronary aortic cusps, giving rise to the left bundle branch which runs superficially just below the endocardium. This mechanism is similar to what happens in TAVI $(13,14)$. However, the incidence of CDs found in our study is lower than what is commonly reported for TAVI (range between $6-30 \%$ for PPI and $77 \%$ for CDs), but higher than that reported for stented bioprostheses (range between $1.6-3 \%$ for PPI and $2.3 \%$ for CDs), and similar to the Perceval-S sutureless valve (Livanova, London, UK) (16.7\% of new onset LBBB and $6.8 \%$ of PPI) (14-16). The cause is probably related to the fact that TAVI does not require annular decalcification, thus the risk of compression and damage to the conduction system is increased. In our study, a larger valve size was identified as the strongest predictor of postoperative CD, similarly to what Romano and colleagues reported (4). In particular, large devices, that require higher inflation pressure (5.0 atm.; sizes: 25 and
$27 \mathrm{~mm}$ ), were associated with new onset CDs, early and also at 1-year follow-up, probably because they generate more myocardial edema or microscopic myocardial injury. In support of this hypothesis, previous studies on TAVI $(13,14)$ reported that the most frequent postoperative CD was LBBB. Our data show LBBB rate of $57.5 \%$ and an overall incidence of $80 \%$ of left-sided CDs. Left-sided CDs are likely related to the close anatomic relationship between the left bundle branch and the aortic valve apparatus. Furthermore, the development of a postoperative LBBB in patients with preoperative RBBB may lead to a complete AV block. Nevertheless, the presence of a preoperative right-sided CD appeared as one of the most powerful predictors of PPI in our analysis, as in previous studies on transcatheter, sutureless, and standard surgical prostheses (4,13-17). For this reason we don't recommend implantation of a RDB in patients with preoperative RBBB. At one-year follow-up, around $60 \%$ of postoperative CDs were still present, while nearly $40 \%$ recovered or improved, including two patients who were not PM dependent anymore. All recovered and improved patients had LBBBs or other left-sided disorders at discharge. This result is in line with our previous study that showed that $6.8 \%$ of transient CDs were all LBBB and recovered during hospitalization (5). Furthermore, there are also studies on TAVI that show a recovery of intraventricular conduction over time (14). A possible explanation is that these transient disorders are due to myocardial edema and small traumas that recover over time. In postmortem specimens from patients with new AV block after TAVI, microscopic analysis demonstrated myocardial injury as 


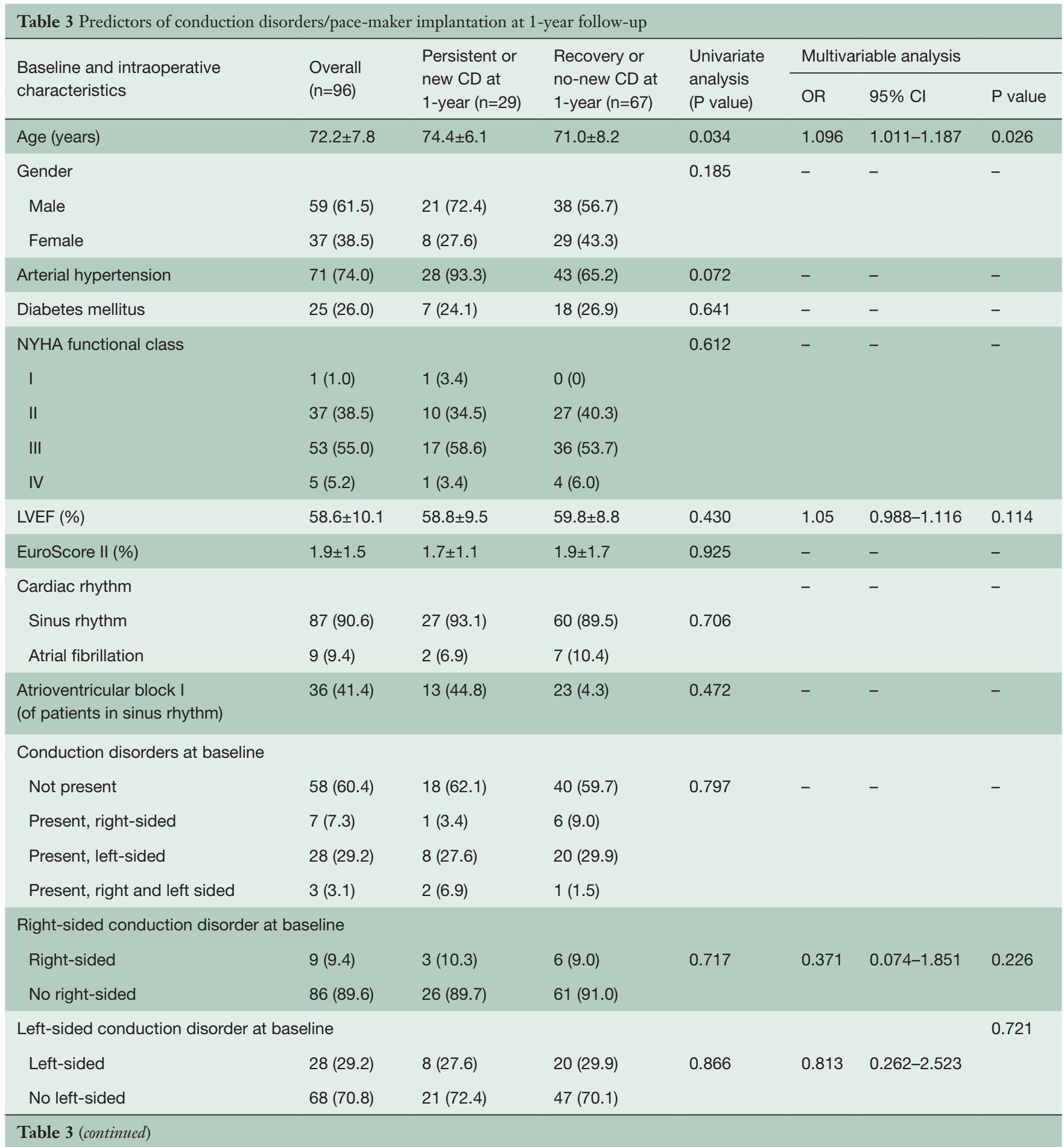




\begin{tabular}{|c|c|c|c|c|c|c|c|}
\hline $\begin{array}{l}\text { Baseline and intraoperative } \\
\text { characteristics }\end{array}$ & $\begin{array}{l}\text { Overall } \\
(n=96)\end{array}$ & $\begin{array}{l}\text { Persistent or } \\
\text { new CD at } \\
1 \text {-year }(n=29)\end{array}$ & $\begin{array}{l}\text { Recovery or } \\
\text { no-new CD at } \\
1 \text {-year }(n=67)\end{array}$ & $\begin{array}{l}\text { Univariate } \\
\text { analysis } \\
\text { (P value) }\end{array}$ & OR & $95 \% \mathrm{Cl}$ & $P$ value \\
\hline \multicolumn{8}{|l|}{ Type of operation } \\
\hline Isolated AVR & $55(57.3)$ & $18(62.1)$ & $37(55.2)$ & 0.696 & - & - & - \\
\hline Mitral replacement & $1(1.0)$ & $1(3.4)$ & $0(0)$ & & & & \\
\hline ASD closure & $3(3.1)$ & $1(3.4)$ & $2(3.0)$ & & & & \\
\hline Type of procedure & & & & 0.635 & & & \\
\hline Isolated AVR & $55(57.3)$ & $18(62.1)$ & 37 (55.2) & & - & - & - \\
\hline Aortic cross-clamp time (min) & $87.5 \pm 33.7$ & $87.9 \pm 33.9$ & $86.0 \pm 33.3$ & 0.814 & 0.995 & $0.956-1.036$ & 0.802 \\
\hline \multicolumn{8}{|l|}{ Surgical approach } \\
\hline Full sternotomy & $85(88.5)$ & 27 (93.1) & $58(86.6)$ & 0.622 & - & - & - \\
\hline Minimally invasive approach & $11(11.5)$ & $2(6.9)$ & $9(13.4)$ & & & & \\
\hline \multicolumn{8}{|l|}{ Prosthesis size } \\
\hline $19 \mathrm{~mm}$ & $9(9.4)$ & $0(0)$ & $9(13.4)$ & 0.039 & - & - & - \\
\hline $21 \mathrm{~mm}$ & $22(22.9)$ & $6(20.7)$ & $16(23.9)$ & & & & \\
\hline $25-27 \mathrm{~mm}$ & $33(34.4)$ & $16(55.2)$ & $17(25.4)$ & & & & \\
\hline Intraoperative complications & $0(0)$ & $0(0)$ & $0(0)$ & 1 & - & - & - \\
\hline
\end{tabular}

well as localized hematoma in the interventricular septum at the site of stent expansion (18). The other independent risk factor for CDs at 1-year was age. It is well-know that older age, independently from cardiac surgery, is associated with a higher rate of development of CDs such as sicksinus-syndrome and bundle branch block due to fibrosis and changes in the conduction system that happen as a result of aging (19-21). Our data show that $8.6 \%$ of patients without new CDs at discharge, experienced a new CD or a PM- implantation at 1-year. However, only 1 patient developed a left-sided disorder at follow-up ECG. In this subset of patients we can hypothesize that new or worsening CDs at 1 -year were not valve-related, but rather age-related events.

\section{Limitations}

The main limitation of this study are related to the retrospective nature of this study, to the inclusion of 
only one center, to the relatively small sample size and to a possible selection bias due to surgeon's preference in the choice of the device. Furthermore, the lack of a control group that includes patients undergoing AVR with conventional stented bioprostheses may represent another limitation. However, the rate of both PPI and CDs in these patients is well known from previous studies.

\section{Conclusions}

According to our data, new-onset CDs or worsening of preexisting CDs is frequent after AVR with RDB. However, one third recover within one year and there is no evidence of worsening over time. Patients receiving larger valve sizes are more likely to develop CDs postoperatively.

\section{Acknowledgments}

None.

\section{Footnote}

Conflicts of Interest: The authors have no conflicts of interest to declare.

Open Access Statement: This is an Open Access article distributed in accordance with the Creative Commons Attribution-NonCommercial-NoDerivs 4.0 International License (CC BY-NC-ND 4.0), which permits the noncommercial replication and distribution of the article with the strict proviso that no changes or edits are made and the original work is properly cited (including links to both the formal publication through the relevant DOI and the license). See: https://creativecommons.org/licenses/by-nc-nd/4.0/.

\section{References}

1. Piazza N, Onuma Y, Jesserun E, et al. Early and persistent intraventricular conduction abnormalities and requirements for pacemaking after per- cutaneous replacement of the aortic valve. JACC Cardiovasc Interv 2008;1:310-16.

2. Kocher AA, Laufer G, Haverich A, et al. One-year outcomes of the Surgical Treatment of Aortic Stenosis With a Next generation Surgical Aortic Valve (TRITON) trial: a prospective multicenter study of rapid-deployment aortic valve replacement with the EDWARDS INTUITY Valve System. J Thorac Cardiovasc Surg. 2013;145:110-5; discussion 115-6.

3. Barnhart GR, Accola KD, Grossi EA, et al. TRANSFORM (Multicenter Experience With Rapid Deployment Edwards INTUITY Valve System for Aortic Valve Replacement) US clinical trial: performance of a rapid deployment aortic valve. J Thorac Cardiovasc Surg 2017;153:241-251.e2.

4. Romano MA, Koeckert M, Mumtaz MA, et al. Permanent Pacemaker Implantation After Rapid Deployment Aortic Valve Replacement. Ann Thorac Surg 2018;106:685-90.

5. D'Onofrio A, Bagozzi L, Tessari C, et al. Evaluation of conduction disorders after aortic valve replacement with rapid deployment bioprostheses. Innovations (Phila) 2018;13:356-60.

6. Malaisrie SC, Mumtaz MA, DiGiorgi PL, et al. Best practices of aortic valve replacement with the Edwards Intuity Elite valve. Ann Thorac Surg. 2020;109:1289-93.

7. Nashef SA, Roques F, Sharples LD, et al. EuroSCORE II. Eur J Cardiothorac Surg 2012;41:734-44; discussion 744-5.

8. Surawicz B, Childers R, Deal BJ, et al. AHA/ACCF/ HRS recommendations for the standardization and interpretation of the electrocardiogram: part III: intraventricular conduction disturbances: a scientific statement from the American Heart Association Electrocardiography and Arrhythmias Committee, Council on Clinical Cardiology; the American College of Cardiology Foundation; and the Heart Rhythm Society. endorsed by the International Society for Computerized Electrocardiology. J Am Coll Cardiol. 2009;53:976-81.

9. Strauss DG, Selvester RH, Wagner GS. Defining left bundle branch block in the era of cardiac resynchronization therapy. Am J Cardiol 2011; 107:927-34.

10. Strauss DG. Differentiation between left bundle branch block and left ventricular hypertrophy: implications for cardiac resynchronization therapy. J Electrocardiol 2012;45:635-9.

11. Brignole M, Auricchio A, Baron-Esquivias G, et al. 2013 ESC Guidelines on cardiac pacing and cardiac resynchronization therapy: the Task Force on cardiac pacing and resynchronization therapy of the European Society of Cardiology (ESC). Developed in collaboration with the European Heart Rhythm Association (EHRA). Eur Heart J 2013;34:2281-329.

12. Epstein AE, Di Marco JP, Ellenbogen KA, et al. ACC/ AHA/HRS 2008 Guidelines for device-based therapy of cardiac rhythm abnormalities: a report of the American College of Cardiology/American Heart Association Task 
Force on Practice Guidelines (writing committee to revise the ACC/AHA/NASPE 2002 guideline update for implantation of cardiac pacemakers and antiarrhythmia de- vices) developed in collaboration with the American Association for Thoracic Surgery and Society of Thoracic Surgeons. J Am Coll Cardiol. 2008;51:e1-e62.

13. Calvi V, Puzzangara E, Pruiti GP, et al. Early conduction disorders following percutaneous aortic valve replacement. Pacing Clin Electrophysiol 2009;32:S126-30.

14. Fraccaro C, Buja G, Tarantini G, et al. Incidence, predictors, and outcome of conduction disorders after transcatheter self-expandable aortic valve implantation. Am J Cardiol 2011;107:747-54.

15. Kogan A, Sternik L, Beinart R, et al. Permanent pacemaker insertion following isolated aortic valve replacement before and after the introduction of TAVI. Pacing Clin Electrophysiol 2015;38:424-30.

16. Lam KY, Akca F, Verberkmoes NJ, et al. Conduction disorders and impact on survival after sutureless aortic valve replacement compared to conventional stented

Cite this article as: D'Onofrio A, Tessari C, Bagozzi L, Migliore F, Filippini C, Cibin G, Pesce R, Francescato A, Gerosa G. Conduction disorders after aortic valve replacement with rapid-deployment bioprostheses: early occurrence and one-year evolution. Ann Cardiothorac Surg 2020;9(5):396-407. doi: 10.21037/acs-2020-surd-14 bioprostheses. Eur J Cardiothorac Surg 2019;55:1168-73.

17. Rahmanian PB, Eghbalzadeh K, Kaya S, et al.

Determination of risk factors for pacemaker requirement following rapid-deployment aortic valve replacement. Interact Cardiovasc Thorac Surg 2018;27:215-21.

18. Moreno R, Dobarro D, Lopez de Sa E, et al. Cause of complete atrioventricular block after percutaneous aortic valve implantation: in- sights from a necropsy study. Circulation 2009;120:e29-e30.

19. Lakatta EG, Levy D. Arterial and cardiac aging: major shareholders in cardiovascular disease enterprises: Part I: aging arteries: a "set up" for vascular disease. Circulation 2003;107:139-46.

20. Lamas GA, Lee KL, Sweeney MO, et al. Ventricular pacing or dual-chamber pacing for sinus-node dysfunction. N Engl J Med 2002;346:1854-62.

21. Spadaccio C, Rainer A, Mozetic P, et al. The role of extracellular matrix in age-related conduction disorders: a forgotten player? J Geriatr Cardiol 2015;12:76-82 . 